\title{
SOBRE A QUESTÃO DA ESCOLA SOCIALISTA: UMA APROXIMAÇÃO AOS ESTUDOS DE KRUPSKAYA
}

\author{
SOBRE LA EMISIÓN DE LA ESCUELA SOCIALISTA: UN ENFOQUE PARA LOS \\ ESTUDIOS DE KRUPSKAYA
}

\section{ON THE ISSUE OF SOCIALIST SCHOOL: AN APPROACH TO KRUPSKAYA STUDIES}

DOI: http://dx.doi.org/10.9771/gmed.v12i3.38586

\author{
Antonio Marley de Araújo Stedile1 \\ Viviane Alves de Oliveira Feitosa ${ }^{2}$ \\ Maria Cleide da Silva Barroso 3
}

Resumo: A Escola Socialista foi pensada para o ensino politécnico, com a formação dos estudantes alinhada a categoria trabalho, onde as habilidades e forças são potencialmente desenvolvidas e empregadas conforme as habilidades de cada indivíduo. O objetivo desse trabalho é investigar a contribuição de Nadejda Krupskaya para a luta pela emancipação da classe operaria. A organização desse movimento se desenvolve na escola, preparando os jovens para o trabalho de forma livre, e assim, o ensino torna-se significativo e dentro da realidade que os jovens estão inseridos. O Sistema por Complexos é aplicado nas escolas socialistas de forma a superar falhas que o ensino tradicional tratava a organização do trabalho e da formação coletiva.

Palavras-chaves: Escola, Trabalho, Krupskaya, Sistema por Complexos, Formação.

Resumen: La Escuela Socialista fue diseñada para la educación politécnica, con la formación de estudiantes alineados a la categoría laboral, donde las habilidades y fortalezas se desarrollan y emplean potencialmente de acuerdo con las habilidades de cada individuo. El objetivo de este trabajo es investigar la contribución de Nadejda Krupskaya a la lucha por la emancipación de la clase trabajadora. La organización de este movimiento se desarrolla en la escuela, preparando a los jóvenes para el trabajo con libertad, y así, la enseñanza se vuelve significativa y dentro de la realidad en la que los jóvenes se insertan. El Sistema Complejo se aplica en las escuelas socialistas con el fin de superar las deficiencias que la educación tradicional trató en la organización del trabajo y la formación colectiva.

Contraseñas: Escuela, Trabajo, Krupskaya, Sistema Complejo, Entrenamiento.

Abstract: The Socialist School was designed for polytechnic education, with the training of students aligned to the job category, where the skills and strengths are potentially developed and employed according to the skills of each individual. The aim of this work is to investigate Nadejda Krupskaya's contribution to the struggle for the emancipation of the working class. The organization of this movement develops at school, preparing young people for work freely, and thus, teaching becomes significant and within the reality that young people are inserted. The Complex System is applied in socialist schools in order to overcome shortcomings that traditional education dealt with in the organization of work and collective training.

Keywords: School, Work, Krupskaya, Complex System, Training.

\section{Introdução}

Em uma sociedade burguesa a função da escola é estabelecida pela preferência da classe dominante, assim todo propósito da função educativa é subordinado aos interesses da elite. Deste modo, a finalidade de todo processo educativo vai ser distinto, modificando de acordo com a parcela do público a 
qual a educação se destina. Se a instrução for reservada aos filhos da classe dominante, ela será um espaço que ofertará cuidados e mimos, instruirá para que concebam os princípios da ideologia de seu grupo social para que no futuro assumam funções de dominância para governar a população.

De acordo com Krupskaya (2017), no que se refere ao ensino público que é ofertado aos filhos dos trabalhadores, a burguesia almejava interferir no que é assimilado pela juventude. A escola oficial ofertava aos alunos saberes básicos, pois existia por parte do governo a compreensão de que assim seria mais simples de operar o povo.

A escola pública até recentemente era uma escola de ensino. Ela dava aos estudantes alguns conhecimentos elementares: governar massas alfabetizadas é mais fácil do que lidar com pessoas que não são capazes de ler os regulamentos internos ou ordens do governo, que não podem assinar o seu nome [....] A escola lhes dá o conhecimento, mas é um presente grego, ela fornece o conhecimento sob a condição de assimilação da ideologia burguesa pelos estudantes. (KRUPSKAYA, 2017, p. 67)

O culto ao prestígio, ao dinheiro são preceitos exaltados pela educação burguesa que coadjuva a apagar qualquer sentimento de irmandade, exaltando entre os alunos um caráter competitivo, suprimindo qualquer espírito de classe, desta forma, os jovens se tornariam um grupo submisso possível de dominação. Essa função da escola apresenta-se de forma mais dissimulada de acordo com a fase de evolução dos países, porém os seus objetivos mantêm-se os mesmos.

Nadejda Krupskaya nasceu na cidade de São Petersburgo no dia 26 de fevereiro de 1869, sua família tinha algumas posses, mas não eram considerados ricos para o período em que viviam, filha de pai militar e mãe professora. Krupskaya inicia sua atividade no magistério ainda na adolescência, quando aos 14 anos dava aulas como professora particular e aulas noturnas para operários. Quando foi presa por questões políticas que se desenrolava na Rússia, ela foi levada pra a Sibéria onde lecionava dentro da prisão, nesse mesmo período de prisão ela se apaixona por Vladimir Ulianov, mais conhecido por Lenin, onde se casam, ficando junto ao seu amado até a morte dele.

Após o período de exilio em Ufá, ela escreve seu primeiro folheto intitulado por: A mulher trabalhadora, que idealiza um regime proletário com poder de torna as mulheres participantes da sociedade retirando-as do papel de dona do lar. Krupskaya não deixa de abordagem as diversas funções das mulheres na sociedade, onde ela aborda a mulher em sua função materna, que se insere como pertencente da história da Rússia e da mulher trabalhadora como colaboradora da classe trabalhadora/operaria alinhada com os ideais marxistas.

$\mathrm{Na}$ obra escolhida para a elaboração do texto foi percebido a articulação entre a categoria trabalho com a educação para a elaboração de um sistema de ensino que colabore para o desenvolvimento pleno das crianças e da juventude soviética advinda da classe trabalhadora e operária. Em seus escritos realiza algumas demonstrações de como se fundamenta a escola do ensino e a escola do trabalho (Escola soviética). Onde na primeira se pensa em uma escola onde os interesses da burguesia sejam atendidos, até mesmo quanto a disposição do grupo que irá ser atendido. Este modelo educacional visa a construção de um conhecimento científico, porém negligencia a formação humana do ser perante a comunidade em que ele se insere. A escola do trabalho busca levantar questões que colaborem para o desenvolvimento do ser de forma integral, 
associando a construção do conhecimento por meio de conceitos, científicos, linguísticos e sociais, contribuindo para a evolução coletiva da sociedade.

\section{Referencial teórico}

Em alguns países como na Rússia, Alemanha e Inglaterra não aceitavam ou resistiam ao acesso dos filhos dos trabalhadores a determinado grau de instrução. A Inglaterra oferecia a possibilidade de bolsas de estudos aqueles alunos mais habilidosos e dóceis dos primeiros ensinos, assim presenteavam com a oportunidade de cursar o ensino médio, porém a burguesia se mostrava preocupada com a oferta de instruir a classe operária, poderiam desabituar do trabalho braçal, então seria necessário que essa medida se restringissem para alguns, os mais inteligentes que deixariam o meio do proletariado para se tornar mão de obra qualificados para a elite.

Ademais, os trabalhadores saiam perdendo, pois despossavam vindouros guias que eram aliciados por uma falsa ideia de pertencimento a uma classe que ele nunca fará parte. Era evidente que a instrução era para poucos beneficiados, na Rússia a burguesia proferia a necessidade de uma reforma do sistema escolar, pois compreendia quanto mais eficiente o processo de escolarização, mais controles teriam do povo.

Aqui na Rússia, a burguesia muito falou sobre a educação geral sobre a reforma do sistema escolar, e não só falou, mas também trabalhou no sentido de implementar estas reformas na prática. Ela fazia isso porque estava bem ciente de que quanto mais perfeita a escola burguesa, mas perfeito seria seu instrumento de escravização das massas (KRUPSKAYA 2017, p. 69).

É necessário governantes comprometidos com a classe trabalhadora em defesa dos seus interesses, no que se refere a promover uma escola para todos, que seja alcançável a todas as parcelas da sociedade. Só assim, a educação deixará de ser uma regalia das camadas mais altas. Sua destinação seria instrumentar todos baseados em uma teoria e uma prática em que todas as pessoas fossem capazes de efetuar qualquer espécie de trabalho, seja ele mental ou físico.

O objetivo da escola condiciona toda a organização do trabalho escolar, todo o modo de vida da escola, todo o conteúdo do ensino escolar e da educação. Se procedermos de acordo com os interesses da burguesia, este objetivo vai ser diferente, variando a dependência de para qual segmento da população a educação se destina (KRUPSKAYA 2017, p. 65).

Nesta perspectiva, o espaço escolar tem como obrigação consolidar e inserir nos jovens a tendência social, de que o trabalho é o alicerce da sociedade humana, educar para que a juventude, enxergue o trabalho como algo rico que faz o indivíduo seja emancipado para sociedade a qual ele pertence. Segundo Krupskaya (2017, p.75): “o trabalho produtivo não só transforma uma criança em um membro útil da sociedade no futuro, mas também faz da criança um membro útil na sociedade no presente, e a consciência deste fato pela criança tem um enorme valor educativo". Difundir que o trabalho tem uma essência coletiva colabora para o ofício cooperativo, onde, proporciona e favorece uma convivência em grupo.

Porém, a escola moderna, no ensino primário, não fortalece, não conecta a ação das crianças no que se refere ao trabalho ou a vida dos adultos. Ela desabitua, reprimindo todos os interesses sociais. $\mathrm{Na}$ segunda etapa da escolarização é considerado um período em que os jovens internalizam as informações e 
suas competências adquiridas por si mesmo ou através da sociedade. Fase essa indispensável que tenha sido aprendido a prática do trabalho e da vida social. No ensino médio, é reforçado todas aquelas inclinações do ensino primário, anulação da individualidade, centrando em uma erudição através dos livros. Na escola superior, seu objetivo é o domínio de determinado segmento.

A escola burguesa deu muitos exemplos de como organizar o trabalho produtivo das crianças. A organização de brigadas de trabalho e de jardim, o auxílio na produção de estatísticas, na separação e distribuição de correspondências, na costura e tricô de roupas quentes para os soldados na limpeza das ruas por crianças de escolas americanas, na fabricação de alimentos, na contabilidade gerencial, na definição de falsificação de produtos, na distribuição de cartazes e literatura, na produção dos manuais de ensino e etc. (KRUPSKAYA, 2017, p.77).

Já na escola socialista sua destinação é a promoção multilateral plena dos jovens, que não anula suas necessidades. Nela os estudantes serão capazes de transparecer sua individualidade em uma função que possua préstimo ao social. Um segundo atributo da escola socialista potencializar o trabalho produtivo nos jovens. Krupskaya (2017), apresenta que a introdução do trabalho produtivo no relacionamento da vida cotidiana e o ensino torna o indivíduo cem vezes mais vivo e profundo, onde, não conduz os jovens a serem fundamentais para sua comunidade no amanhã, ela estabelece que essa juventude seja prestativa hoje.

A escola socialista só consegue emergir em algumas conjunturas sociais, porque seus propósitos estão baseados no essencial de uma comunidade socialista, para além da sociedade de classes. Essa possibilidade ajusta quando existe um domínio de um governo popular que seus avanços se dão com o apoio social, esse comando se respalda no bem-estar do sujeito e do coletivo, que extingue com o arcaico padrão educandário de classes.

Formado nesta escola o jovem cai, saindo da escola, para uma atmosfera que minimiza muito rapidamente todos os benefícios dessa educação. Numa sociedade baseada na divisão do povo em "ossos brancos" e "ossos pretos", ou seja, em pessoas "inteligentes", por um lado, e operários braçais por outro, o estudante deverá escolher a um ou a outro tipo de trabalho, e sua capacidade de trabalhar "multilateralmente" ficará atrofiada (KRUPSKAYA, 2017, p. 76-77).

Em uma escolarização socialista todos são formados para o trabalho manual e intelectual. Dessa forma, o cidadão seja versátil de acordo com as necessidades do trabalho. Instruir o povo com a ideia de que o trabalho tem que transcender para além da submissão, para uma ocupação voluntária: "Caçar de manhã, pescar a tarde, pastorear à noite e fazer crítica depois da refeição” (Marx, 2011, p.78).

Por meio de Nadezhda Krupskaya, a pedagogia soviética incorporou a estrutura da teoria do materialismo histórico dialético à concepção de educação. Com isso o trabalho educativo, trabalho socialmente necessário, politecnia, entre outros, apresentam-se por meio dos professores e dirigentes da educação soviética. Nesse modelo seriam apresentados as dificuldades e fetiches criados a partir de uma construção pedagógica responsável pela organização escolar soviética.

O método por complexos desejado por Krupskaya para os soviéticos, busca fazer relação entre os estudos das coisas e fenômenos de uma maneira ampla, de forma que se alcance a totalidade e a complexidade dos processos que rodeiam nossa sociedade. Ele é um método científico, o que o torna um 
método de estudo, abordando temáticas que tenha aproximações com a realidade dos envolvidos. Apresentamos mais sobre a sua proposta no desenvolvimento deste texto.

\section{Desenvolvimento}

A escola soviética, da classe trabalhadora escolheu usar esse sistema porque os dois são amparados com o mesmo pensamento que seria a ideologia marxista como o materialismo histórico. $\mathrm{Na}$ sua compreensão as pessoas vivem e com elas a necessidade de preencher suas carências básicas como: comer, vestir, morar. E para atender essas necessidades, precisam fazer uso do trabalho para que assim, supram as demandas necessárias para sua sobrevivência. Com as mudanças da sociedade e com elas as relações de produção.

Para a professora Nereide Saviani o ponto de vista de uma educação socialista é formar o homem para o trabalho, pois na concepção do materialismo histórico, os seres humanos se instruem e se transforma na mesma proporção que constitui uma relação de modificação da natureza. Já a instituição escolar suas funções e modificações são estabelecidas de acordo com a sociedade vigente e seu contexto histórico.

Porém, sustentada nos princípios socialistas, prover uma instrução completa, oportunizando o acesso a todos os saberes que foram construídos socialmente ao longo dos anos. Para que a compreensão de todos esses conhecimentos gere a emancipação de uma classe.

Saviani (2018), explicita que os princípios de uma educação socialista é disponibilizar uma formação que manifeste os múltiplos aspectos do indivíduo, que essa instrução entenda que os eventos sociais historicamente determinados, são concebidos através das relações sociais e estão incutidos de ideologia de classe. A importância da instrução escolar como expressão da educação no sentido absoluto, constituindo-se um meio essencial ao ensino. Na qual esse ensino deveria ser estruturado com a expectativa primordial da formação do pensamento científico.

O método dos complexos é um procedimento de estudo, ele não pode ser considerado com uma técnica didática, ele é um método da ciência que é utilizado na realização das pesquisas. Em relação ao ensino a proposição da utilização como sistema de ensino é que as disciplinas não sejam lecionadas de forma fragmentadas, separadas umas das outras, pois a importância do uso do sistema de complexos é porque ele está centrado na totalidade dos fenômenos.

\footnotetext{
Por complexo deve-se entender a complexidade particular de um fenômeno tomando da realidade e que reúne ao seu redor determinado tema central ou ideia. O conceito de complexidade no ensino inclui em si ligação, a união, a unificação, mas não se limita a isso. (KRUPSKAYA, 2017, p 313)
}

Na visão de Krupskaya (2017), essa maneira de ordenação conduziu a educação escolar a um distanciamento da realidade cotidiana dos alunos. Ela esclarece que para que aconteça a aprendizagem nas crianças é só estabelecer proximidade da realidade prática em que elas vivem. Exemplificando: o estudo de química de alguns conceitos pode ser apreendido na elaboração de um bolo e de como o fermento age na massa e no forno quando está assando. Para que se efetive o modelo de ensino por complexos, podemos 
seguir uma carta metodológica apresentada por Krupskaya na obra A construção da pedagogia socialista.

Detalharemos a carta que é dividida em 8 estágios.

\section{Carta metodológica}

\section{Essência do sistema de ensino por disciplinas e sua diferença com o sistema por complexos:}

A principal diferença entre os dois é que no sistema de disciplinas ocorre em muitos casos a falta de interdisciplinaridade e com isso, as matérias acabam sendo passadas de formas isoladas e sem relação com conteúdo de outras disciplinas, ou outras temáticas que os professores considerem "fuga" do conteúdo principal.

No sistema de complexos ocorre a busca pela totalidade, onde os professores trabalham de maneira cooperativa, vislumbrando a descoberta da criança de acordo com seus avanços cognitivos e assim, possam desbravar as diversas áreas das ciências.

\section{O Sistema por Complexos na GUS}

A ideia do sistema de complexos se efetiva na interdisciplinaridade, uma relação pensada a muito tempo, onde segundo Platão, possa existir a harmonia entre todas as ciências e elas se relacionem entre si.

A comissão cientifica estatal - GUS designava que o trabalho tinha que ser colocado como ponto central para onde seriam indicadas as ações nas escolas. E esse sistema por complexos seria o responsável de relacionar entre si as disciplinas, como relacionar com a preparação para o trabalho associado.

Em sua atividade de trabalho, dirigida para a satisfação de suas necessidades, a pessoa procura por bens, precisa deles para a natureza e para usá-los aplicando seus instrumentos tecnológicos. Para sua maior garantia na luta pela existência, as pessoas de longa data se reúnem em uma organização social; dessa forma, a sociedade humana constitui-se em processos de organização da atividade de trabalho das pessoas (KRUPSKAYA, 2017, p.314).

Com o crescimento da mais-valia, a sociedade por sua vez, distancia cada vez mais os níveis existentes e com isso as classes sociais passam a diferenciar as pessoas pelas relações na produção, consumo e renda. Nesse momento, observa-se a intervenção desses trabalhadores que serão formados pelas escolas do trabalho na luta pela superação dessas classes.

Os temas escolhidos para os complexos nos programas são escolhidos não ao acaso, arbitrariamente. Toma-se exatamente aquilo que, em primeiro lugar, é necessário para resolver os desafios socioculturais que são colocados para a escola em seu meio circundante. (KRUPSKAYA, 2017, p. 316)

Esse despertar do trabalhador para a necessidade da escolarização, se faz urgente. O processo de sair da cegueira à realidade que eles estão submetidos permite organizar suas habilidades de forma que todos possam colaborar com suas particularidades e forças para a efetivação de um processo plural. Os professores necessitam de uma orientação maior, para repassar aos alunos tudo aquilo que irá colaborar com a formação para o trabalho. 


\section{Lugar e caráter da complexidade nos vários níveis de ensino}

Nas escolas de primeiro grau (equivalente ao ensino fundamental), tem-se o papel do professor polivalente, onde um mesmo professor é responsável por todas as disciplinas, no segundo grau (equivalente ao ensino médio), já tem-se a designação de diferentes professores para as disciplinas e nesse movimento perceber a variância de ideias e de metodologias, não descaracterizando que o professor do primeiro grau irá utilizar uma única metodologia para todas as disciplinas, porém seu viés ideológico percorrerá em unidade.

No sistema por complexos existe cada professor para uma área da ciência diferente, que se unem com o mesmo intuito de conduzir os alunos para um sistema que valorize as forças de trabalho e assim trabalhe e fortaleça o que cada um tem a oferecer.

\section{Distribuição temporal das tarefas no sistema de ensino por complexos}

A organização se dá por trimestralidade de acordo com as condições climáticas correspondente a cada trimestre. Entretanto, algumas regiões não se adaptam a essa lógica, devido as variâncias do clima, sendo assim, as escolas possuem a liberdade de realizar a adaptação respeitando a particularidade de cada região.

A organização mensal é mais simples se fazer e distribuir, onde é proposto para a organização escolar através de um material que serve de apoio metodológico e organizacional, porém a organização diária depende exclusivamente da escola e dos professores, pois isso é algo que vai da particularidade e do fluxo em que a sala de aula se constitui.

O ambiente escolar pode possibilitar aos professores do segundo grau tenham mais dificuldades de aplicar o sistema por complexos, devido a falta de alguns materias didáticos e o a disposição do espaço físico da escola, que em alguns casos delimitam até onde pode se alcançar uma liberdade de execução de sua disciplina por cada professor,onde, mesmo com a flexibilidade de se trabalhar temas diversificados em suas aulas, eles precisam se procupar até onde a temática abordada será relevante na matéria e vice-versa. Os professores necessitam ter um bom diálogo entre si para que estejam em sintonia com os conteúdos abordados e os espaços da escola.

A diversidade de grupos na escola permite que os trabalhadores colaborarem seguindo algumas técnicas relatadas pela autora:

a. A um grupo dá-se trabalho independente, e outro grupo exercita-se com o professor.

b. Técnica do "fogo cruzado", quando por alguns minutos o professor conversa com um grupo e dá a ele, por exemplo, uma tarefa, deixando-o a ponderar, e vai para outro grupo: conversando e dando a este outro grupo uma tarefa, volta de novo o primeiro grupo, e assim por diante.

c. Parte do dia o professor ocupa-se com um grupo, a outra parte, com o outro (é possível também que em uma parte do dia se ocupe com dois grupos, e na outra parte com o outro). 
d. Um dia ocupa-se de um dos grupos, outro dia, ocupa-se de outro grupo.

Essas formas auxiliam os professores a torna menos cansativo a rotina docente e possibilitam que os estudantes tenham independência para observarem os fenômenos que ocorrem no cotidiano de cada um, e assim, realizem anotações, esboços, representações e trabalhos manuais, tudo isso pode ser atribuído um caráter avaliativo pela lógica da escola soviética do trabalho.

\section{O papel dos diferentes métodos no ensino por complexos}

O método dos complexos determina o estudo do objeto, e assim, realiza as determinações para que se selecione o material de pesquisa, o planejamento e o fenômeno ocorrido. O método do trabalho, do laboratório, excursão, ilustrativo, de observação, o heurístico de conversação e de exercitações formais, são inseridos no ensino por complexos, assim, a criança/adolescente realize processos de trabalho de acordo com sua faixa etária, estimulando a superação de obstáculos e superando barreiras na construção do conhecimento.

\section{Exigência metodologicas para os complexos}

A autora (KRUPSKAYA, 2017, p.329 à 321), define pontos que a organização e planejamento para que se efetive o ensino por complexos:

- É necessário que os temas dos complexos não sejam arbitrários.

- O complexo não deve constituir-se como um conglomerado mecânico: a ligação das partes deve impor-se naturalmente.

- O tema não deve ser demasiado estreito. Assim, por exemplo, seria sem sentido um complexo que tomasse o tema "carreira" ou "estudante" e desse um longo tempo para o desenvolvimento de tal complexo. Entretanto, na prática, tais casos podem ser encontrados.

- O tema deve ser tal que ele dê possibilidade para envolver todos os estudantes dos grupos no trabalho ativo.

- O tema deve colocar aos estudantes problemas reais para serem resolvidos independentemente, com a ajuda do professor, e não permitir que as informações do professor sejam dadas prontas, deixando os estudantes serem apenas ouvintes passivos.

- Cada tema separado não deve ser isolado dos outros temas; todos os temas devem ligar-se em um único sistema, e em sua formulação deve observar-se a sequência definida.

- No desenvolvimento do tema, o professor deve garantir, que tanto o momento da observação, como o momento da expressão, no porcesso cognitivo, sejam a tal ponto desenvolvidos que haja bastante material para a aquisição de habilidades e hábitos no campo das contas (matemática), no campo da fala (linguagem), do trabalho e das artes. 
- No estudo de um determinado tema, não é necessário agregar inutilidades. Não deve afastar-se muito da essência do tema e da sua ideia central, como se faz muitas vezes, tentando abarcar obrigatoriamente tudo que vem à cabeça em ligação como estudo de um dado tema.

\section{Objeções ao sistemas de ensino}

Se tem muitas dificuldade para que se concretize o sistema por complexos devido a baixa preparação dos professore para tal método. Isso, entretanto, não é uma objeção ao sistema, pois, ele é capaz de conduzir os estudantes na escola do trabalho de forma supere as dificuldades e obstáculos que impedem a concretização desse método.

O professor de formação também é estimulado a avaliar-se e procurar metodologias que contribuam para o porcesso do ensinar-aprender, e assim formar ótimos operários e camponeses para a Russia.

Os espaços físicos das escolas também são limitadores de uma ampliação da universalidade do ensino, porém, como prentende-se que o aluno incorpore o conhecimento construido na escola em seu cotidiano, eles superam os espaços fisicos escolares.

Não se deve pensar que nesse sitema por complexos os alunos "aprenderão" menos do que no sistema tradicional de ensino, pois, a escola possui atividades sufcientemente capazes de incorporar todos os principios fundamentias para que se efetive o letramento, a lógica matemática, o desenvolvimento científico e a produção artistica.

\section{O que o professor deve fazer para concretizar o sistema por complexos.}

Se faz necessário conhecer o caminho metodológico que a GUS incorpora em seus programas; conhecer a realidade, por meio de bibliografias ou experiências em outros espaços escolares que utilizem o método por complexos; a aplicação desse sistema deve ser estudada de forma coletiva; realizar estudos experientais por meio de complexos específicos que a escola aborde; ser familiarizado com temática como: cultura, religião, geografia espacial, politica, relações sociais; Realizar estudos etnográficos para despertar o maior envolvimento e comprometimento dos alunos com a diversidade social e cultura de nosso planeta.

\section{Considerações finais}

Percebe-se que o papel do professor no processo da elaboração do modelo de educação soviética é de fundamental importância. Krupskaya (2017), afirma que a partir da auto-organização as crianças encontram formas de ações que envolvam diversas pessoas pensando, organizando e executando a escola do trabalho com uma visão que colabore para a formação do ser revolucionário.

Nessa investigação compreende-se que com a Revolução Russa, revolução socialista exigiam transformações na economia, na ciência e na educação que equilibrasse o processo de transformação de uma sociedade capitalista para a socialista. Para subsidiar essa mudança requeria um sistema educacional 
concebido a partir das demarcações revolucionárias com suporte dos fundamentos marxistas, indo ao encontro de uma concepção educativa para a criação de um novo homem para a sociedade soviética, contrastando com aquele formado a partir da educação da sociedade burguesa.

Alguns pedagogos ousados contribuíram com esse trajeto, entre eles, Pistrak, Lunacharsky, Makarenko, Schulguin e Krupskaia ${ }^{4}$, os quais nos detivemos neste estudo. Todos eles se dedicaram na busca de uma nova escola soviética, baseada no trabalho como elemento fundante e auto organizada pelo proletariado, que organizasse aqueles que iriam reestruturar essa nova sociedade.

Na perspectiva da educação soviética, essa escola tinha o dever de agregar a cultura e a ciência com a política socialista, porque essa educação, essa formação, não poderia se afastar da essência que é a luta de classe, em tempo algum.

Existia a clara consciência que havia distinção da oferta de ensino e do que era lecionado para os filhos da elite e aos filhos do proletariado. Era fundamental recusar essa educação burguesa. Para transformar esse modelo, a escola deveria fornecer a todos o acesso aos conhecimentos reunidos ao longo dos anos.

Neste artigo, tendo como base os estudos explorados por Krupskaya (2017), mostrou-se que embora a metodologia de complexo de estudo da educação socialista, tenha sido um conhecimento ímpar, a concepção que a fundamenta, o materialismo histórico, continua vigente e colaborando para o entendimento da realidade social e educacional. O estímulo desta temática foi compreender as particularidades dessa experiência, distante do atual período histórico brasileiro, elementos que ainda hoje influenciam práticas emancipatórias no sistema educacional.

Entende-se que as contribuições da educação socialista procuraram traçar ensinamentos norteadores para uma pedagogia revolucionária gerando uma reflexão da conexão do trabalho ao processo educativo que contribua para uma formação omnilateral, na qual todos são concebidos os princípios para o trabalho coletivo.

\section{Referências}

CIAVATTA, Maria. Mediações históricas de relação trabalho e educação. Gênese da disputa na formação dos trabalhadores (1930-1960). Rio de Janeiro: Lamparina / CNPq / FAPERJ, 2009

FRIGOTTO, Gaudêncio; CIAVATTA, Maria. Trabalho como princípio educativo. In: CALDART, Roseli S. et al. Dicionário Educação do Campo. Rio de Janeiro/São Paulo: EPSJV/Expressão Popular, 2012.

KRUPSKAYA, N.K. A construção da pedagogia socialista. São Paulo: Expressão Popular, 2017.

MOURA, Severina Mártyr Lessa de. O "socialismo real": gênese da influência marxista na educação brasileira / Severina Mártyr Lessa de Moura. - 2017. 212f.

SAVIANI, Nereide. Educação Socialista. Germinal: Marxismo e Educação em Debate, Salvador, v. 10, n. 2, p. 232-239, Ago. 2018. 
1 Instituto Federal do Ceará - IFCE - Campus Fortaleza. Orcid: http://orcid.org/0000-0002-7594-4925 E-mail: mstedille@gmail.com

2 Instituto Federal do Ceará - IFCE - Campus Fortaleza. Orcid: http://orcid.org/0000-0002-4757-7793 Email: vivi.ufc@hotmail.com

3 Instituto Federal do Ceará - IFCE - Campus Maracanaú. Orcid: https://orcid.org/0000-0001-5577-9523 E-mail: ccleideifcemaraca@gmail.com

${ }^{4}$ Grande parte desse grupo de intelectuais militantes soviéticos participou do NARKOMPROS (Comissariado do Povo para a Instrução), instituído em 1917 e atuante até 1946, ano em que passou a ser intitulado como Ministério de Educação.

Recebido em: 27.08 .2020

Aprovado em: 01.09.2020 